\title{
IFTAR Business Process and Strategies: A Study of IFTAR Shop in Rangpur City-Corporation
}

\author{
Md. Shahinoor Rahman, Md. Morshadul Hasan Arif*, Md. Shafiul Islam \\ Department of Accounting and Information Systems, Begum Rokeya University, Rangpur, Bangladesh \\ Email address: \\ shahin_brur@gmail.com (Md. S. Rahman), arif.morshad@gmail.com (Md. M. H. Arif), shafiul.pbrur@gmail.com (Md. S. Islam) \\ *Corresponding author
}

\section{To cite this article:}

Md. Shahinoor Rahman, Md. Morshadul Hasan Arif, Md. Shafiul Islam. IFTAR Business Process and Strategies: A Study of IFTAR Shop in Rangpur City-Corporation. Science Journal of Business and Management. Vol. 4, No. 4, 2016, pp. 127-131.

doi: $10.11648 /$ j.sjbm.20160404.14

Received: June 26, 2016; Accepted: July 11, 2016; Published: August 2, 2016

\begin{abstract}
The main purpose of this article is to know and make people informed about various IFTAR items available in Rangpur city-corporation and to know the marketing approach - the marketers of IFTAR shop use. This is not only the culture of Rangpur but all over the country except expensive and highly developed area of Bangladesh. IFTAR is one of the most informed and available culture of Muslim customs. As Bangladesh is a Muslim country IFTAR is also an important customs in the month of RAMADAN. This paper will show the basic characteristics of IFTAR business and their strategy in this business. Different countries have different culture. Especially for IFTAR, every Muslim country sets for IFTAR as their culture. But their items differ area to area, city to city, country to country even customs to customs. Bangladesh is Muslim country and north-bangle is one of the most influential area in this economy so the customs and culture of this arena also influential in the economy. Rangpur is one of the most valuable cities because every type of life leading facility is presence here such as Medical College, Public University, Dental College, many privet university, many international agency and many MNC also. So in this paper the researcher tried to capture the culture and mostly thing this culture will represent the IFTAR culture of Bangladesh.
\end{abstract}

Keywords: IFTAR, IFTAR Business Strategy, IFTAR Business Process, IFTAR in Bangladesh

\section{Introduction}

Ramadan is the $9^{\text {th }}$ month according to Islamic lunar calendar. Ramadan is derived from Arabic root word (Ramida or Arramad) that means intense scorching heat and dryness especially of the ground. The most interesting moment is IFTAR time. IFTAR refers to the evening meal when Muslims break their fast at the time of sunset right. This report will give a review of total IFTAR habit and culture of Rangpur city as well as a view of Bangladesh. The residential of this city have some common items in their IFTAR with some special items. All of the groups or classes (upper, middle \& lower) are the target group of the marketers. They provide all sorts of IFTAR items by considering the economic capabilities of all classes of customers. Here, the main purpose was to find out the IFTAR culture, IFTAR habits and pons and corns of IFTAR business.
All the information of this paper is authentic and pure field oriented. The practical field of IFTAR market is a unique view in every area. A model IFTAR shop showed in this paper. This shop will represent the overall habits of IFTAR product. In this model IFTAR shop, it has shown to keep the reasonable price for student and used some promotional tools considering our business's cost and profit.

\section{Methodology}

The researcher used the independent survey method for this research. They carried out this research by surveying both directly and indirectly. Direct ways were physical survey by the researcher and indirect survey was not physically. At first the issue "IFTAR" was selected as a common culture but exceptional for the research publications. Rangpur city-corporation as the research field was selected by researchers because Rangpur is the city 
where every class of people is living. So different classes of people have different cultures of braking their fast. As the culture is different, the way to have IFTAR by different class of people is different. That's why researchers tried to explore those cultures of IFTAR having by people of Rangpur City as well as the Business of IFTAR in Rangpur City. After selecting the research field researchers prepared a questionnaire consisting 22 questions, these 22 questions were related with the IFTAR product, pricing strategy, promotional activities, packaging systems, costing and advertising procedure etc. Researchers surveyed about 15 samples. These samples were surveyed physically by the researcher and all the data and information collected from the person or respective employee in that IFTAR shop. Besides these primary sources of data/information, researchers collected the secondary information from the website of Rangpur Chamber of Commerce and also got information from internet and different text books. After collecting that information from both primary and secondary source researchers decorated all these information according to the research objectives

\section{Theoretical Overview}

a. Overview of Rangpur City-Corporation:

Table 1. Information about Rangpur city-corporation [Data source: Wikipedia].

\begin{tabular}{ll}
\hline Location & $25^{\circ} 34^{\prime} \mathrm{N} 89^{\circ} 15^{\prime} \mathrm{E} / 25.56^{\circ} \mathrm{N} 89.25^{\circ} \mathrm{E}$ \\
Total Area & $-28 \mathrm{~km}^{2}(11 \mathrm{sq} \mathrm{mi})$ \\
Total Population & $650,000[2012]$ \\
\hline
\end{tabular}

Sources of Income: Business, Farming, Mango Gardening, Factory, Tobaco Service etc.

Level of population social status; $60 \%$ people are middle class status (annual income below 300000 per year).

\section{b. IFTAR}

IFTAR is one of the well-known culture and habit for the Muslim all over the world. It is the culture of RAMADAN month. The most interesting moment of this month is IFTAR time. IFTAR refers to the evening meal when Muslims break their fast at the time of sunset.

c. Tools or elements of marketing elements (4Ps):

1) Product - A product is anything that can be offered to a market to satisfy a needs or wants

2) Price-Price is amount of money that customers have to pay to obtain the product or service

3) Place-Place includes company's activities that make the product available in target market

4) Promotion-Promotion includes all activities that communicate the merits of the product or service and pursue target market to buy it.

d. Pricing strategy for new product:

There are two types of pricing strategy followed by the marketers.

1) Market Skimming: High price in initial stage.

2) Market Penetration: Low price in initial stage.

e. Pricing strategies for existing product:

I. Cost plus price: Retailer uses it.

Price $=$ Fixed cost + variable cost + profit

II. Mark-up pricing: It is used by manufacturing company.

Price $=\frac{\text { Unit } \cos t}{1-\text { Markup }}$

III. Target return pricing: Marketers charge pricing depending on initial investment.

$\mathrm{TRP}=$ Unit cost $+\frac{\text { desiredreturn }}{\text { Unitsales }} *$ initialinvestment

IV. Going rate: Following the competitor's price.

f. Promotional Tools:

There are several promotional tools used by the marketers to make the product and service known to the consumer and customers. These are

1. Advertising: Advertising is one of the most influencing tools for business promotion

2. Personal selling: Personal selling is the most ancient tools for promoting the product or business

3. Sales promotion: Lots of activities that promote sale.

4. Public relations: Public relation is also a good promotional tools.

5. Direct and Online marketing: Now a day's online marketing takes the best place for marketing.

\section{Findings of This Research}

This surveyed included 10 IFTAR shops at Rangpur City Bazar.

Collected information of the survey -

a) Items available and price

b) Pricing strategies used

c) Promotional tools used

d) Cost, Profit and employees

a. Items available and price:

All of the below stated items and their piece is used in Rangpur city-corporation.

Table 2. Charts of IFTAR items and prices.

\begin{tabular}{|c|c|c|c|c|c|}
\hline \multicolumn{6}{|c|}{ NAME OF ITEMS AVAILABLE } \\
\hline Common Items & & KABAB & & & \\
\hline Jilapi & $100 /-\mathrm{kg}$ & Jali Kabab & $10 /-$ & Special Bundia & $140 /-$ \\
\hline Piaju & $3 /-$ & Tika Kabab & $10 /-$ & Chitui Pitha & $5 /-$ \\
\hline Alur chop & $3 /-$ & Shali Kabab & $10 /-$ & Mutton chop & $5 /-$ \\
\hline Sobjir chop & $5 /-$ & Shick kabab & 40/- & Chicken & $50 /-$ \\
\hline Begun chop & $5 /-$ & Chicken Grill & $300 /-$ & Noodles & $160 /-$ \\
\hline Bundia & $100 /-$ & Laddu & $160 /-$ & Vegetable role & 20/- \\
\hline
\end{tabular}




\begin{tabular}{|c|c|c|c|c|c|}
\hline \multicolumn{6}{|c|}{ NAME OF ITEMS AVAILABLE } \\
\hline Common Items & & KABAB & & & \\
\hline Chhola boot & $100 /-$ & Khorma & $120 /-$ & Chicken fry & $50 /-$ \\
\hline Chanachur & $100 /-$ & Kacci Birani (plate) & $120 /-$ & Chicken grill & $300 /-$ \\
\hline Nimokpora & $100 /-$ & Shahi Halim & $30 /-$ & Pati shapta pitha & $20 /-$ \\
\hline Chira vaza & $100 /-$ & Borhani & $60 /-(1 / 5)$ & Dim Chop & 10/- piece \\
\hline Chana Polao & $150 /-$ & Bhuna khichuri & $15 /-$ & CURD- $120 /-\mathrm{kg}$ & \\
\hline Khejur & & Boot birani & & & \\
\hline Borai & $200 /-(\mathrm{kg})$ & Mihi dana & $150 /-$ & Tok doi & $70 /-\mathrm{kg}$ \\
\hline \multirow{2}{*}{ Sowdi morium } & \multirow{2}{*}{$400 /-(\mathrm{kg})$} & \multirow{2}{*}{ Jorda polau } & \multirow{2}{*}{$140 /-$} & Lacchi & 30/-glass \\
\hline & & & & Faluda & 40/-glass \\
\hline Modina (pakisthani) & $180 /-(\mathrm{kg})$ & Sada doi & $160 /-$ & deleted & \\
\hline Iraqee & $120 /-(\mathrm{kg})$ & Butter oil laccha & $320 /-$ & & \\
\hline \multicolumn{6}{|l|}{ Fruit juice: } \\
\hline \multicolumn{6}{|l|}{ Apple--50/-glass } \\
\hline \multicolumn{6}{|l|}{ Mango--40/- glass } \\
\hline Others--40/- glass & & & & & \\
\hline
\end{tabular}

b. Pricing Strategies used:

The actual pricing strategy is - Cost plus pricing. Because their selling items are IFTAR and these are existing item in all shops. They add profit with their production cost. They can use rapid penetration pricing for some special items by modifying product. Such as - different flavor of juice. There are some product these are not made by them and some of these have directly tax added with the value.

In case of product pricing, there are two types of product sales; single per piece and aggregate (kg or quantity). Some basic item such as PIYAJU, ALU CHP, BEGUN CHOP, MUTTON CHOP, SHOBJI CHOP etc. is piece sales type product. Another common items are such as CHOLA BOOT, BURINDA, JILAPI, KHEJUR, MURI etc. are quantity sales type product

c. Promotional tools used:

- They use a gorgeous banner in front of their shop. Sometimes they use their banner in front of super market, in front of Jahaj Co., in front of city bazar and some other important place.

- They provide in different package.

- Attractive Packet (Sometime the leveled their company name in the packet).

- $2 / 3$ persons calling customers (advertising); this is the common scenario for every IFTAR shop.

- Employee's well dressed up; sometimes every shop has unique dress code. Its works like as branding

- Parcel service; sometime they provide IFTAR for different program or contract basis or as program budget.

d. Cost, Profit and Employee:

Cost: Cost varies per items in different shop and their daily total production and another influencing factor is daily price change in commodity market.

Profit: Depends on differences between sales price and the production cost. Profit also depend on the cost of commodity and the price change of the materials.

Employee: Employed by the workers according to their production.

\section{Analysis of This Research}

To complete this report, the information of this paper collected physically and directly from the salesperson, management and finally from the owner. Those data show that there are many items those are similar in most of the IFTAR shop. The similar items are BOOT, BURINDA, CHANAHUR, NIMOKPARA, PIYAJU, BEGUNI, ALU CHOP, SHOBJI CHOP etc. But we got some different information from different shops about their special items. Such as:

- [All the words that are misspelt in English dictionary are the BANGLADESHI Foods].

- MOUBHASA IFTAR SHOP offers-SHAHI JILAPI, Special HALIM, Mutton HOTCHPOTCH, KHASI TIKA.

- IFTAR SOMAHAR offers- BHUNA HICURI, Special MURI.

- SAYED BEKARI Special IFTAR and Laccha offersSana Polau, Boot Biriani, Mihi Dana, Jorda Polao

- Mohua special IFTARi and Ghie Bhaja Laccha Offers--Sada Doi, Muhuar Butter Oil Laccha, Tok Doi,

- MITHU Hotel Offers---Chicken Fry, Noodles, Vegetable Roll, Chicken Grill, Patishapta Pitha, Jail kabab.

- ALLAH'r Dan IFTAR shop offers- Kurmur and Sana Polau.

- Prince Hotel and Restaurant offers-Sali kabab, Jail Kabab, Dim Chop, Tika Kkabab.

- Moubon special IFTAR offers-4 types of KHEJUR (Borai, Saudi Morium, Modina, Iraqi), Khurma, Kacchi Biriani, Shahi Halim and Borhani.

a. Pricing:

We surveyed 10 IFTAR shops. All shops provide many items of IFTAR at different prices but we realized that the all marketers of those shops follow the cost plus profit strategy. They set the price by adding a reasonable profit with their production cost. After analyzing their given information we have understood that they follow the rapid market penetration 
pricing strategy.

b. Promotional tools:

We observed physically that all the IFTAR shops have colorful and attractive banner but some IFTAR shops recruit two or more persons to advertise their shops in front of their shops. Some IFTAR shops provide different colorful and attractive packet and some IFTAR shops recruited workers those are well dressed up.

c. Employees:

Majority of IFTAR shop have 10-15 employees but MOUBON special IFTAR recruits 25 employees and MAHUA special IFTAR has 35 employees, New PIASI special IFTAR has 30 employees to serve and ensure the healthy $\&$ hygienic IFTAR and service to the customers.

\section{Model IFTAR Shop}

\section{Exclusive Kabab's and IFTAR House.}

a. General Items:

General items contain all of the item which is available to every IFTAR shop. As this paper is showing a model of IFTAR shop so every general item should be presented in the shop. This is IFTAR's fundamental commodities. The below stated items are the general items;

Table 3. List and Price of General Items.

\begin{tabular}{lllll}
\hline Serial. & Name of the items & Price per Item & Serial. & Name of the items \\
\hline 1 & Jilapi & $99 /-\mathrm{kg}$ & 7 & Chhola boot \\
2 & Piaju & $4 /-$ & 8 & Chanachur \\
3 & Alur chop & $4 /-$ & 9 & Nimokpora \\
4 & Sobjir chop & $4 /-$ & 10 & Chira vaza \\
5 & Begun chop & $4 /-$ & 11 & Nimki \\
6 & Bundia & $95 /-\mathrm{kg}$ & 12 & Muri \\
\hline
\end{tabular}

b. Special Items:

Table 4. List and Price of Special Items.

\begin{tabular}{lll}
\hline Sl. No. & Name of Items & Price \\
\hline 1 & Jarka & $5 /-$ \\
2 & Bograr special doi & $99 /-\mathrm{kg}$ \\
3 & Sami Kabab & $40 /-$ \\
4 & Tika Kabab & $10 /-$ \\
5 & Buti Kabab & $20 /-$ \\
6 & Shik Kabab \& Nun (Package) & $25 /-$ \\
7 & Chicken Roll & $20 /-$ \\
8 & Vegetable Roll & $10 /-$ \\
9 & Mutton Roll & $15 /-$ \\
10 & Akboriar Ghie bhaja special Laccha & $99 /-\mathrm{kg}$ \\
11 & Lacchi & $25 /-$ \\
12 & Faluda & $35 /-$ \\
13 & Halim & $40 /-$ \\
& Special sorbot & \\
& Banana Flavor & $30 /-$ \\
& Orange Flavor & $20 /-$ \\
14 & Apple & $20 /-$ \\
& Pineapple & $30 /-$ \\
& Strawberry & $20 /-$ \\
& Lichi & $20 /-$ \\
\hline
\end{tabular}

The items which is not available to every IFTAR shop is called special IFTAR items. As this paper is showing a model of IFTAR shop so it should include the special items besides the every general item should be presented in the shop. These are the characterized IFTAR's products. The below stated items are the special items;

c. Number of the employees:

As this is the model IFTAR shop and everything of this model is imaginary and based on the above finding from the Rangpur city corporation, there should be needed minimum 15 employees to maintain the overall activities and business.

d. Parcel price:

Every package and its price will Varies on items.
Table 5. Package Price.

\begin{tabular}{ll}
\hline Campus package & $49 /-$ \\
Couple package & $69 /-$ \\
Family package & $99 /-$ \\
\hline
\end{tabular}

As this model characterize 1 to 99 prizing so the price should start with 1 and limiting 99 taka. The pricing packaging systems are given below;

Campus Package: Campus package is for the single person and for the single student. Especially it is mention for the single person both male and female. The pricing strategy for campus price is also for single one is only 49 taka (Bangladeshi Currency).

Couple Package: Couple package for the couple group such as husband and wife, 2 friends, 2 partner and 2 collogue. It is a better option because when the campus package is 49 taka there's couple price is only 69 taka. So for two people IFTAR program it is better pricing and economy.

Family Package: Family contains a group of members. S this package contains IFTAR for a family. If there are 3 member in a family then their individual cost will 147 taka but in this package this cost will minimize to only 99 taka.

e. Promotional tools:

(1) 1-99 Pricing: First promotional tools is 1 to 99 pricing is available. It is always an attractive pricing. This pricing will create value for the IFTAR product

(2) Banner: As it is a new systems and package for IFTAR world so banner is important for informing the people for the new systems. The important residential place can be covered by banner advertisement.

(3) Special parcel service: New idea is special parcel service for IFTAR product. The contact no. for parcel service provided in banner.

(4) Advertising on local TV channel \& Newspapers, 
Facebook: Television is one of the most important area of advertisement. Maximum coverage of advertisement covered by television TV channel. Not only television channel but also the national and local newspaper is also an important media for advertisement. Maximum people ages $45+$ years prefer newspaper to television. Besides TV channel and Print media, Facebook is one of the most influencing media of advertisement. Every young ages of people are connected through social network. So informing the young age's people, Facebook can play the important role.

(5) Quality assurance: Quality is an important and crucial factors for developing the business. People always prefer quality to price. They always seek assurance for the perfect quality. Quality is the best preference to the public.

(6) Advertising in Publication: The university and college student always a good intention to read various types of books or publication. So advertising in publications can be a better way.

(7) Direct Marketing: Direct marketing is the best ways to direct sell. So there no doubt for direct marketing capturing power.

(8) Personal Sales: Personal sales and direct marketing almost same ways. So personal sales can be the better option also like as direct marketing.

(9) Prize (Coupon): Now a day's coupon is one of the most attractive ways to capture the customer, there are lots of coupon policy for the IFTAR package.

\section{Recommendation and Conclusion}

After observing the needs and wants of the people of city corporation, Rangpur, this paper have showed that in the month of Ramadan people wants to get some special items in their IFTAR in a reasonable price. As Rangpur is a city of peace, Rangpur is the city of education and Rangpur is the city of medical and business, so it is a place of middle class society. As it is not so developed and industrialized, very costly IFTAR items are not acceptable and these are beyond the purchasing power of common people. Most of the people are student so, their needs and wants are limited. By considering this we want to develop a shop of 1 to 99 taka. Here, the model shop will provide all IFTAR items less than 99 taka with 3 sorts of packages (campus, couple and family). The researcher hopeful that this model shop will be able to satisfy the needs of the area and can earn a reasonable profit.

\section{References}

[1] Agriculture Food and Rural Development. Methods to Price Your Product; Agriculture Business Startegies 9 Feb 1999, Agdex 845-2)

[2] Arvinlucy Akinyi Onditi. An Evaluation of Promotional., International Journal of Business and Social Science (Vol. 3 No. 5; March 2012)

[3] Chai Lee Goi (May 2009). A Review of Marketing Mix: 4Ps or More (Vol. 1, No. 1); International Journal of Marketing Studies

[4] Cole Ehmke, Joan Fulton, and Jayson Lusk. Marketing's Four P's First Steps for New Entrepreneurs; PURDUR EXTENSION EC-730

[5] David J. Teece (2010). Business Model, Business Strategy and Innovation; Elsevier Ltd

[6] Dennis E. Schlais, Richard N. Davis, Kristi A. Schlais; Introduction to Business (Third Edition)

[7] How to achieve an effective promotional mix; The Chartered Institute of Marketing, 2009

[8] Philip T. Kotler and Kevin Lane Keller (2010). Marketing Management; A South Asian perspective. Pearson Education, India

[9] Philip T. Kotler and Kevin Lane Keller (2006). Principles of Marketing; Pearson Education

[10] Ramon C. Masanell, J. Enric Ricart. From Strategy to Business Model and to Tactics; Harvard Business School Working Paper 10-036

[11] Rangpur City-Corporation; Wikipedia 